\title{
Manifestaciones misceláneas de COVID-19
}

\author{
Miscellaneous manifestations of COVID-19 \\ María Graciela Guzmán Perera, * Eduardo David Poletti Vázquez ${ }^{\ddagger}$ \\ Citar como: Guzmán PMG, Poletti VED. Manifestaciones misceláneas de COVID-19. Acta Med \\ Grupo Angeles. 2021; 19 (s1): s42-s47. https://dx.doi.org/10.35366/101027
}

\section{Resumen}

Existen dermatosis descritas asociadas directamente a la infección por SARS-CoV-2 y que no pueden clasificarse como parte de los cinco grupos de manifestaciones cutáneas de la infección. Las mucosas no presentan con frecuencia manifestaciones clínicas, aunque se acompañan de algunos cuadros descritos en la literatura. Desde que empezamos a conocer la enfermedad nos dimos cuenta de que era capaz de imitar cualquier cuadro clínico, sobre todo los relacionados con problemas reaccionales autoinmunes y/o causados por medicamentos así como otros virus. Su fisiopatología no se conoce y parece involucrar los sistemas de defensa del huésped así como el metabolismo de algunos medicamentos que pueden producir moléculas intermedias con cierta toxicidad o actuar como antígenos.

Palabras clave: Eritema, exantema, mácula, pápula, glositis, conjuntivitis.

\section{Abstract}

There are descriptions of dermatoses directly associated to the SARS-CoV-2 infection that cannot be classified between the five groups of cutaneous manifestation of the disease. Mucosal damage is not very frequent, but some clinical pictures have been described in the literature. Since we began to learn COVID-19, we realize that this virus has the capability to produce imitation for almost all severe drug reaction manifestations, reactional autoimmune problems or lesions produced by other active viruses. Its physiopathology seems to be complex and involve the defensive mechanisms of the host against the virus. Drug metabolism and intermediate products, can act as antigens or toxic products that can induce strong reactions.

Keywords: Erythema, exanthem, thrush, papules, glossitis, conjunctivitis.

\section{INTRODUCCIÓN}

Para tratar de cubrir en su totalidad las manifestaciones asociadas a la infección por el virus SARS-CoV-2, es necesario agregar un sexto apartado a la clasificación de Galván y Casas. ${ }^{1}$ Las afecciones de las mucosas que acompañan en algunos casos a la enfermedad y las reacciones cutáneas son similares a las dermatosis medicamentosas graves, aunque no son muy frecuentes, requieren ser incluidas en un nuevo capítulo para abarcarlas en su totalidad. Su fisiopatología se desconoce, y podría ser que la inmunosupresión causada por el SARS-CoV-2 propicie la reactivación de infecciones herpéticas 6.7 o por EBV. Los medicamentos y sus metabolitos podrían tener un papel importante cuyo mecanismo aún desconocemos, los describiremos por separado.

\section{SÍNTOMAS MUCOSOS}

1. Síntomas orales: son escasos los casos de afección oral que se han reportado en la literatura, la más

\footnotetext{
* Dermatóloga del Hospital Ángeles Pedregal, Ex-Presidenta de la Academia Mexicana de Dermatología, la Fundación Mexicana para la Dermatología y colmexiderma.

₹ Dermatólogo e internista, práctica privada, Aguascalientes, profesor de la Universidad Autónoma de Aguascalientes y la Universidad Cuauhtémoc, ex-presidente de la Sociedad Mexicana de Cirugía Dermatológica y Oncológica. Colmexiderma.
}

\section{Correspondencia:}

María Graciela Guzmán Perera

Correo electrónico: graceguzman07@gmail.com

www.medigraphic.com/actamedica (1) 
importante sin duda es la pérdida del gusto (ageusia), se presenta en $29.28 \%$ de los casos. ${ }^{2}$ También se han reportado enfermos con afecciones orales: los grupos Carreras-Presas y colaboradores ${ }^{3}$ y Hedou y Jiménez-Cauhe y su equipo ${ }^{4}$ han informado siete casos con dolor gingival difuso, gingivitis descamativa así como úlceras y ampollas orales. Estas manifestaciones se relacionaron con "eritema polimorfo-like" asociado a COVID-19, aunque también se sospechó infección agregada de tipo herpético precipitado por la intubación.

Las lesiones pueden ser de tipo eritematoso o purpúrico. Los lugares involucrados con más frecuencia son: $38 \%$ lengua, $26 \%$ mucosa labial, $22 \%$ paladar, $8 \%$ encías, y mucosa yugal 5\%., ${ }^{1,5}$ Las lesiones más frecuentes son las de aspecto aftoso, Riad y colaboradores publicaron una gran serie de 21 estomatitis aftosas, el promedio de edad fue de 31 años, 81\% fueron mujeres, la mayoría no fumadoras, $14.3 \%$ presentaron fiebre persistente, $23.8 \%$ tos y anosmia. El curso de la enfermedad fue leve, las lesiones pueden ser únicas o múltiples y están rodeadas de un halo blanquecino, ${ }^{7}$ pero puede haber lesiones en "blanco de tiro", erosiones, angina ampollosa, queilitis angular y síndrome de Melkersson-Rosenthal. Se pueden presentar desde cuatro días antes hasta 12 semanas posteriores a los síntomas sistémicos. En Turquía encontraron estomatitis aftosa en $5.2 \%$ de los enfermos con manifestaciones cutáneas. ${ }^{8}$

Las lesiones tipo aftoso aparecen como pequeñas úlceras con halos blanco-amarillentos con tendencia a la formación de pseudomembranas. 6,8 Los pacientes jóvenes tienden a formar lesiones más inflamatorias que necróticas. Iranmanesh y colaboradores sugieren en su trabajo que las estomatitis aftosas parecen surgir como consecuencia de una exagerada quimiotaxis de neutrófilos, estrés e inmunosupresión.

2. Úlceras genitales: Falkenhain-López y su equipo ${ }^{9}$ reportaron un caso que inició con úlceras dolorosas en vulva a nivel de los labios menores. En boca se observaron ulceraciones aftosas en la mucosa labial, estas lesiones aparecieron junto con síntomas generales y respiratorios de COVID-19, PCR+. Se descartó la posibilidad de otra etiología de las úlceras.

3. Conjuntivitis: hasta el momento la complicación más frecuente a nivel ocular es la conjuntivitis. Según la revisión de Pérez-Bartolomé y colaboradores esta manifestación puede ser viral o inmunomediada. La asociada al virus puede iniciar antes o después de los síntomas respiratorios, se presenta en forma unilateral o bilateral, tiene presencia típica de folículos y su dura- ción es entre cinco y 20 días. La mediada inmunológicamente acompaña a cuadros inflamatorios sistémicos, sobre todo en niños y se caracteriza por enrojecimiento conjuntival, exantema y febrícula. También acompaña al síndrome de choque tóxico y a los cuadros Kawasaki like. A diferencia de sus predecesores, el SARS-CoV-2 puede ocasionar una conjuntivitis más severa, con marcada hiperemia cilio-conjuntival, queratitis punteada superficial, folículos de la conjuntiva tarsal e incluso con formación de pseudomembranas. ${ }^{10}$

\section{PITIRIASIS ROSADA LIKE}

La pitiriasis rosada de Gibert es una enfermedad cutánea subaguda causada por Herpes 6 y 7 . Se desconoce su mecanismo de transmisión y tiempo de incubación. No es transmisible de persona a persona, pero aparece en "brotes" epidémicos a finales del invierno y principio de la primavera (aunque puede presentarse todo el año). Característicamente inicia con una "placa heraldo" que consiste en una placa eritematoescamosa con borde descamativo, que puede aparecer semanas o días antes del resto de la erupción. Posteriormente aparecen pequeñas placas eritematosas que afectan sobre todo el tórax y la raíz de las extremidades con distribución en "árbol de Navidad", puede haber también grandes placas "en medallón". Su duración es variable, pero prolongada desde seis hasta 12 semanas. Sólo $10 \%$ de los casos se asocian a prurito. Existen formas atípicas que pueden variar en el tiempo de presentación de las lesiones.

La infección por SARS-CoV-2 puede causar también un cuadro similar a la pitiriasis rosada. Ehsani y Merhy ${ }^{11,12}$ describieron dos enfermos, uno de 27 años y otra de 26 con infección COVID-19, erupción clásica con placa heraldo y aparición posterior de lesiones más pequeñas. En ambos casos la dermatosis fue previa a los síntomas respiratorios.

Hemos observado cuatro casos similares, de los cuales tres se presentaron como primera manifestación de la enfermedad.

Drago $\mathrm{F}$ y colaboradores ${ }^{13}$ comunicaron recientemente un caso de un enfermo de 16 años y una dermatosis con placas eritematoescamosas ovales distribuidas en "árbol de Navidad", el paciente había estado en contacto con su padre, quien semanas antes había tenido síntomas de COVID-19. El paciente presentaba leucopenia. Sus anticuerpos anti-HV 6 y 7 fueron positivos IgM e IgG. Asimismo, los anticuerpos IgM anticápside para EBV fueron positivos.

Es posible que esta dermatosis no esté relacionada con COVID-19 en forma directa, pero sí indirecta causando inmunosupresión y propiciando la activación de virus latentes. 


\section{ERITEMA POLIMORFO LIKE}

Tanto en los niños como en los adultos se han descrito cuadros con lesiones típicas en "blanco de tiro" que afectan el tronco, extremidades, palmas y plantas. Esto ha sido reportado con mayor frecuencia en población pediátrica, en quienes se han descartado otras virosis que puedan causar la reacción. En la revisión multinacional de Daneshgaran G y colaboradores se ha presentado en 37/998 casos, es decir, $3.7 \%$, un promedio de edad de 12.2 años y una frecuencia hombre/ mujer de 60/40\% respectivamente. ${ }^{14}$ La mayor parte de los escasos casos reportados con lesiones orales fueron también clasificados dentro de este rubro, con la acepción de que todos los pacientes eran adultos en su mayoría mujeres. ${ }^{14}$

Janah y su equipo ${ }^{15}$ informaron dos casos de pacientes con COVID-19 y lesiones en blanco de tiro con participación palmoplantar. Ambos de sexo masculino, uno de 17 y otro de 28 años de edad presentaban síntomas de COVID-19 y PCR+.

Hay un reporte de cuatro mujeres con una media de edad de 66.75. Las lesiones aparecieron entre 16 y 24 días. Una de ellas había sido dada de alta y desarrolló las lesiones durante la hospitalización y las otras tres después de ser dadas de alta, regresaron a urgencias por la erupción. Los estudios de laboratorio mostraron que algún parámetro de inflamación había empeorado (dímeros D, cuenta de linfocitos o proteína $C$ reactiva), no se encontraron datos de ninguna infección o síntoma asociados a micoplasma o herpes. ${ }^{15}$ Tenían lesiones en "blanco de tiro", afección de palmas y plantas. Habían tomado ácido ascórbico, hidroxicloroquina y azitromicina entre 12 y 15 días después de haber iniciado el tratamiento. Las lesiones empezaron en el tronco y se diseminaron, había enantema petequial en dos de las pacientes. Histológicamente había espongiosis moderada, en la dermis había vasos dilatados llenos de neutrófilos, extravasación de eritrocitos, infiltrado intersticial perivascular linfocítico. Sólo en un caso se observaron cambios de interfase con degeneración vacuolar. Los autores sugieren que está ligado a los efectos de SARS-CoV-2, pero no excluyen que los medicamentos estén involucrados.

Es muy importante en estos casos no olvidar descartar la posibilidad de sífilis secundaria, sobre todo en pacientes con lesiones eritematodescamativas o palmoplantares.

\section{SDRIFE (exantema intertriginoso y \\ flexural simétrico por fármacos)}

La aparición de cuadros similares al SDRIFE parece ser poco frecuente; sin embargo, se ha reportado el caso de una mujer de 64 años de edad, quien cuatro días después de presentar fiebre y síntomas respiratorios o sistémicos relacionados con COVID-19 mostró eritema en zonas intertriginosas (pliegues interglúteo, submamario y axilares). Sólo había tomado paracetamol, lo cual excepcionalmente puede producir SDRIFE. ${ }^{16}$ Hay otro caso reportado por Chicharro y colaboradores de una mujer de 75 años que ingresa al hospital por neumonía y severa hipoxia. Se inició tratamiento con azitromicina e hidroxicloroquina, dos días después empieza con exantema flexural de inicio en axilas y fosas antecubitales, que se disemina al tronco, ingles y cara interna de muslos. La biopsia mostró pústulas subcórneas, infiltrado superficial de linfocitos y eosinófilos así como linfopenia. Se suspendieron los medicamentos y se iniciaron esteroides sistémicos y el exantema resolvió en siete días. ${ }^{17}$

Muchos pacientes presentan manifestaciones mixtas y eso incluye las lesiones flexurales. Es siempre importante descartar la posibilidad del efecto nocivo de los medicamentos que reciben.

\section{DRESS (exantema, eosinofilia y síntomas sistémicos inducido por fármacos)}

Esta reacción a medicamentos ocurre en general por el uso de anticonvulsivantes (carbamacepina, lamotrigina, DFH), antibióticos (minociclina) y la reacción a los antipalúdicos de síntesis (hidroxicloroquina) es más rara. Los síntomas sistémicos son hipertermia, malestar general, hepatitis, reacción leucemoide con eosinofilia, linfocitosis atípica, tiroiditis, entre otras manifestaciones.

Herman y colegas $^{18}$ reportaron un caso de un enfermo de 50 años de edad que 17 días después de haber sido admitido en el hospital por insuficiencia respiratoria por COVID-19, presentó exantema macular diseminado con afección de $70 \%$ de la superficie corporal, edema intenso de la cara y las manos. Había recibido azitromicina, hidroxicloroquina, propofol, sufentanil, clonidina, heparina, sevoflurano, cefalexina, flucloxacilina y norepinefrina para su tratamiento. El laboratorio reveló leucocitosis, linfocitos atípicos, eosinofilia, elevación de marcadores de inflamación: dímero-D, azoados y transaminasas. Se descartó infección por virus Epstein-Barr, CMV, HIV y hepatitis B/C. En este caso no hubo posibilidad de asociar la dermatosis a un fármaco en especial, se sospechó de la hidroxicloroquina, aunque no es el fármaco que con más frecuencia lo causa. Existe otro caso reportado por Sernicola y colaboradores ${ }^{19}$ de un enfermo de 70 años con un cuadro florido de neumonía COVID-19 en el que se utilizó tocilizumab cuando iniciaron los síntomas de "tormenta" inflamatoria. El paciente presentó eritema generalizado horas después de la administración del medicamento y elevó considerablemente la cuenta de eosinófilos. Se manejó con 20 mg de metilpredinisolona y no se presen- 
taron síntomas o signos de afección sistémica para poder llamarlo síndrome de DRESS, ya que es posible que el tratamiento con glucocorticoides haya bloqueado la reacción. Desgraciadamente por razones de seguridad, no fue posible hacer pruebas de alergia. En la mayor parte de los enfermos no se ha realizado investigación de la activación de los virus ni degranulación de basófilos, liberación de factor inhibidor de los magrófagos o pruebas epicutáneas para la búsqueda del o los medicamentos involucrados. Aun así, si las pruebas resultan negativas no se excluye la participación de algún medicamento.

Al parecer la desregulación de los linfocitos T reguladores interfiere en la activación de la reactivación de los herpes virus (HH6, varicela zoster). Además de la activación de estos virus, las repuestas inmunológicas antivirales y las respuestas inmunológicas contra los medicamentos pueden ser los mecanismos productores de las reacciones que estamos observando en los enfermos con COVID-19. ${ }^{20,21}$

\section{AGEP: PUSTULOSIS SUBCÓRNEA AGUDA EXANTEMÁTICA}

La pustulosis aguda subcórnea es una reacción medicamentosa que corresponde al grupo de las severas. Múltiples medicamentos han sido implicados en su génesis incluyendo los antipalúdicos de síntesis.

Enos $\mathrm{T}$ y colaboradore ${ }^{21}$ describieron el caso de una mujer de 29 años de edad, con antecedente de deficiencia en la proteína S y un supuesto síndrome de StevensJohnson debido al cefaclor. Tuvo un contacto cercano con portador de SARS-CoV-2, se presentó refiriendo hipertermia, tos y dolor de garganta. El PCR aún no estaba disponible. Dados los antecedentes se le inició tratamiento con azitromicina, doxiciclina y prednisona sin mejoría. Ocho días después se le inició hidroxicloroquina 200 mg dos veces al día. Cuatro días después comienza con eritema de la cara, cuello y abdomen que empezaba a diseminarse a las extremidades. Se suspendió la hidroxicloroquina, 12 días después continuaba con exantema generalizado y se había agregado edema en la cara, sin pústulas, signo Nikolsky negativo, mucosa oral hiperémica sin erosiones o exulceraciones. Laboratorio: leucocitosis de 16,700 con neutrofilia y sin eosinofilia, PCR-, biopsia, pústulas subcórneas con neutrófilos y eosinófilos.

Robustelli y colaboradores ${ }^{22}$ describieron otro caso de una mujer de 70 años con historia de psoriasis que ingresó al hospital por un exantema rápidamente diseminado y difuso, con micropústulas pruriginosas. Tres semanas antes había sido tratada por neumonía por SARS-CoV-2 Con lopinavir/ritonavir e hidroxicloroquina por 10 días con buena respuesta. Tres días después de haber suspendido el tratamiento inicia con lesiones maculopapulares en el tercio superior de ambos brazos que diseminaba rápidamente al tronco. Fue tratada con prednisona $0.3 \mathrm{mg} / \mathrm{kg} /$ día. A los siete días de tratamiento no había mejorado y asistió a urgencias con una dermatosis diseminada con una base eritematoedematosa donde se observaban minúsculas pústulas, lesiones en blanco de tiro y escamas. Afectaba la cara, el tronco, los miembros superiores y nalgas con patrón simétrico. Respetaba las mucosas. La biopsia mostró moderada acantosis focal y espongiosis, exocitosis neutrofílica, algunos queratinocitos necróticos, pústulas subcórneas con infiltrado perivascular de neutrófilos y eosinófilos. Se trató con prednisona y se supuso la hidroxicloroquina como probable causa.

En el mes de agosto de 2020 Ayatollahi y colaboradores $^{23}$ describen otro paciente de 33 años que había padecido COVID-19 tres meses antes. En ese tiempo había sido tratado con azitromicina con resultados favorables después de 10 días. No tenía historia de reacciones anormales a otros medicamentos. La dermatosis apareció en forma abrupta afectando cara, cuello, tronco y palmas. Edema y eritema con micropústulas diseminadas. Afebril y buen estado general. PCR- y serología de COVID-19 positiva para IgG y negativa para IgM. Histológicamente mostró paraqueratosis neutrofílica con costras de hipergranulosis focal, acantosis, moderada espongiosis. Edema y ectasia de los capilares con infiltrado perivascular e intersticial de neutrófilos y linfocitos en dermis superficial, algunos eosinófilos.

La pustulosis aguda exantemática habitualmente aparece de 48 a 72 horas después de iniciado el medicamento ofensor. Se han reportado algunos casos asociados a infecciones virales. Aquí la causa parece ser la infección por SARS-CoV-2 con una manifestación tardía. ${ }^{22,23}$

La patogenia de la reacción no ha sido totalmente entendida, pero se considera que es una reacción mediada por células T CD4+, CD8+ y un incremento importante de citoquinas sobre todo elevados niveles de IL-17/22, TNF y factor estimulador de colonias de granulocitos y macrófagos. ${ }^{22,23}$

Los mecanismos productores del daño son similares a los inducidos por SARS-CoV-2, es posible que la tormenta inmunológica se manifieste en forma tardía y puede explicar estas manifestaciones como reacciones atípicas a medicamentos. ${ }^{20-23}$

\section{ENFERMEDAD DE KAWASAKI LIKE Y SÍNDROME INFLAMATORIO MULTISISTÉMICO PEDIÁTRICO (PIMS-TS)}

La enfermedad de Kawasaki consiste en una vasculitis aguda febril que afecta a niños menores de cinco años con relación hombre/mujer de 1.5/1. No se conoce su 
etiología a ciencia cierta, pero se ha asociado a las infecciones respiratorias agudas de origen viral que inducen una inmunidad adaptativa innata muy reactiva que parece estar genéticamente determinada.

Existen casos esporádicos asociados con choque causado por activación masiva de macrófagos y disfunción circulatoria. ${ }^{24,25}$

Como complicación de la pandemia por SAR-CoV-2, la población pediátrica empezó a presentar cuadros similares a la enfermedad de Kawasaki. Según Verdoni y colaboradores se reporta una incidencia 30 veces más grande en la población de Bergamo, Italia. ${ }^{25}$ Los autores demostraron que los niños que padecen COVID-19 y estas manifestaciones eran mayores de cinco años, pero hay pacientes reportados de 21,27, 31 y algunos adultos de más edad con cuadros similares. ${ }^{26}$ Los enfermos tenían importante compromiso cardiaco, afección multisistémica, (cutáneo-mucosa, gastrointestinal, hepática, hematológica, falla circulatoria, neurológica) con más intensidad que en la enfermedad de Kawasaki original, probablemente a cauda de la activación sistémica de macrófagos. ${ }^{24-27}$ La duración
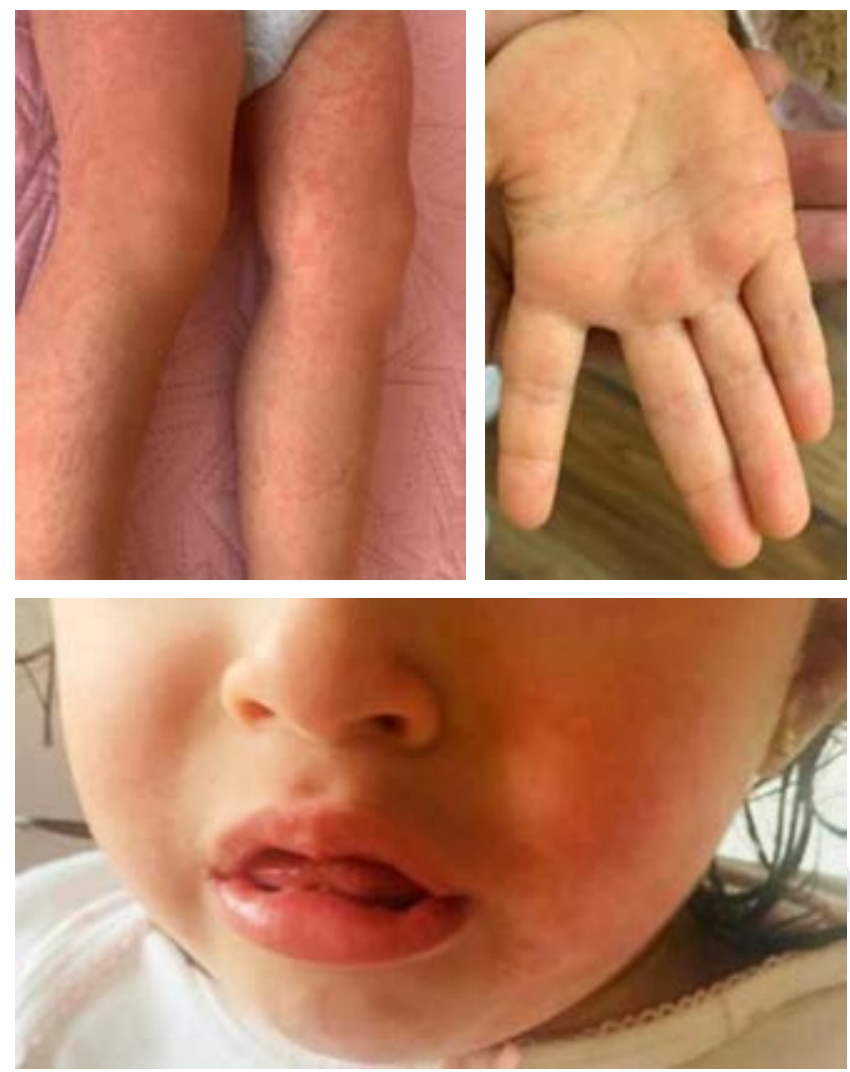

Figura 1: Exantema maculopapular, eritema palmoplantar y facial con queilitis. Característico en enfermos con PIMS (pediatric inflammatory multisystemic syndrome o Kawasaki like). de la fiebre es mayor de cinco días, existe más elevación de los leucocitos, neutrófilos, dímeros-D, ferritina, troponinas, transaminasas; hay disminución de hemoglobina, leucopenia con linfopenia, trombocitopenia, desequilibrio hidroelectrolítico: hiponatremia e hipocalemia y tiempos de coagulación prolongados. ${ }^{25-27}$

Los signos mucocutáneos consisten en conjuntivitis, exantema morbiliforme maculopapular o vesicular. Además existe edema periférico, dolor en las extremidades e importantes síntomas gastrointestinales (diarrea y vómito). Es muy interesante que no tengan síntomas respiratorios severos, pero los cardiacos requieren terapia intensiva con ventilación asistida para su estabilización. El corazón suele estar afectado con miocarditis, pericarditis, aneurismas coronarios, disfunción valvular, insuficiencia ventricular derecha, etcétera. ${ }^{27}$

La PCR en su mayoría es positiva, pero negativa cuando se presenta en forma tardía. En general tiene antecedentes bien claros de contacto con pacientes enfermos de COVID-19. Alrededor de la tercera o cuarta semana de la enfermedad aparecen cuadros producto de "tormenta" inmunológica. ${ }^{23,27,28}$

La vasculitis producida por el SARS-CoV-2 se parece mucho a la encontrada en los casos clásicos de la enfermedad de Kawasaki, pero su etiología no es muy clara. Existe un infiltrado perivascular en "manga de abrigo" compuesto por linfocitos citotóxicos CD8+. La hipereosinofilia suele ser común y algunos autores han pensado que estas células pueden ser las causantes de desencadenar la cascada de coagulación.

La boca suele estar afectada: queilitis, glositis, tonsilitis. La erupción suele ser maculopapular, eritema palmoplantar, por lo general hay linfadenopatía múltiple así como conjuntivitis no supurativa. Se puede asociar con lesiones en "blanco de tiro" y dar cuadros mixtos con eritema polimorfo like. De acuerdo a una serie francesa que incluyó a 16 niños las lesiones cutáneas aparecen en $80 \%$ de los casos, la más frecuente es el exantema maculopapular, seguido del eritema palmoplantar además de queilitis xerótica o costrosa y hemorrágica (Figura 1).24-28

En general estos pacientes no responden bien a inmunoglobulina intravenosa, el tratamiento es con glucocorticoides, anticoagulantes, asistencia y vigilancia cardiovascular.

\section{REFERENCIAS}

1. Galván Casas C, Català A, Carretero Hernández G, RodríguezJiménez P, Fernández-Nieto D et al. Classification of the cutaneous manifestations of Covid-19: a rapid prospective nationwide consensus study in Spain with 375 cases. Br J Dermatol. 2020; 183 (1): 71-77. doi: 10.1111/bjd.19163.

2. Capocasale G, Nocini R, Faccioni P, Donadello D, Bertossi D, Albanese M et al. How to deal with coronavirus disease 2019: A comprehensive 
narrative review about oral involvement of the disease. Clin Exp Dent Res. 2021; 7 (1): 101-108. doi: 10.1002/cre2.332.

3. Carreras-Presas M, Amaro SJ, López-Sanchez AF, Jané-Salas E, Somacarrera-Perez ML. Oral vesiculobullous lesions associated with SARS-CoV-2 infection. Oral Dis. 2020; 27 (S3): 710-712. doi/10.1111/odi.1338231.

4. Hedou M, Carsuzaa F, Chary E, Hainaut E, Cazenave-Roblot F, Masson Regnault M. Comment on "Cutaneous manifestations of COVID-19 a first perspective by Recalcati S. J Eur Acad Dermatol Venereol. 2020; 34 (7): e299-e300. doi/10.1111/jdv16519.

5. Iranmanesh B, Khalili M, Amiri R, Zartab H, Aflatoonian M, Oral manifestations of Covid-19. Dermatol Ther. 2021; 34 (1): e14578. doi: $10.1111 /$ dth.14578.

6. Díaz RM, Jimenez RA, Villarroel M. Oral manifestations associated with Covid-19". Oral Diseases. 2020. doi: 10.1111/odi.13555.

7. Riad A, Kassem I, Stanek J, Badrah M, Klugarova J, Klugart M. Aphthous stomatitis in COVID-19 patients: case-series and literature review. Dermatol Ther. 2021; 34 (1): e14735. doi: 10.1111/dth.14735.

8. Askin O, Altunkalem RN, Altinisik DD, Uzuncakmak TK, Tursen U, Kutlubay Z. Cutaneous manifestations of hospitalized patients with diagnosis of COVID-19. Dermatol Ther. 2020; 33 (6): e13896. doi: 10.1111/dth.13896.

9. Falkenhain-López D, Agud-Dios M, Ortiz-Romero PL, SánchezVelázquez A. COVID-19 related acute genital ulcers. J Eur Acad Dermatol Venereol. 2020; 34 (11): e655-e656. doi: 10.1111/jdv.16740.

10. Pérez-Bartolomé F, Sánchez-Quiroz J. Manifestaciones oftalmológicas del SARS-CoV-2: revisión de la literatura. Arch Soc Esp Oftalmol. 2021; 96 (1): 32-40.

11. Ehsani AH, Nasimi M, Bigdelo Z. Pityriasis rosea as a cutaneous manifestation of COVID-19 infection. J Eur Acad Dermatol Venereol. 2020; 34 (9): e436-e437. doi: 10.1111/jdv.16579.

12. Merhy R, Sarkis AS, Stephan F. Pytiriasis rosea as leading manifestation of COVID-19 infection. J Eur Acad Dermatol Venereol. 2021; 35 (4): e246-e247. doi: 10.1111/jdv/17052.

13. Drago F, Ciccarese G, Rebora A, Parodi A. Human herpesvirus 6, 7 and Epstein Barr virus reactivation in pityriasis rosea during COVID-19. I Med Virol. 2021; 93 (4): 1850-1851. doi: 10.1002/jmv.26549.

14. Daneshgaran G, Dubin DP, Gould DJ. Cutaneous Manifestations of COVID-19: An Evidence-Based Review. Am J Clin Dermatol. 2020; 21 (5): 627-639. doi: 10.1007/s40257-020-00558-4.

15. Janah H, Zinebi A, Elbenaye J. Atypical erythema multiforme palmar plaques lesions due to Sars-CoV-2. J Eur Acad Dermatol Venereol. 2020; 34 (8): e373-e375. doi: 10.1111/jdv.16623.

16. Mahe A, Birckel E, Krieger S, Merkelen C, Bottlaender L. A distinctive skin rash associated with coronavirus disease 2019. J Eur Acad Dermatol Venereol. 2020; 34 (6): e246-e247. doi: 10.1111/jdv.16471.

17. Chicharro P, Rodriguez-Jimenez $P$, Muñoz-Aceituno E, De Argila D, Muñoz-Hernandez P, Llamas-Velasco M. SDRIFE-like rash associated with COVID-19, clinicopathological correlation. Australas J Dermatol. 2020; 62 (1): 88-89 doi: 10.1111/ajd.13444.

18. Herman A, Matthews M, Mairlot M, Nobile L, Fameree L, Jacquet M et al. Drug reaction with eosinophilia and systemic symptoms syndrome in a patient with COVID-19. J Eur Acad Dermatol Venereol. 2020; 34 (12): e768-e700. doi: 10.1111/jdv.16838.

19. Sernicola A, Carnicelli G, Di Fraia M, Chello C, Furlan C, Muharremi $\mathrm{R}$ et al. Toxic erythema and eosinophilia associated to tocilizumab therapy in a COVID-19 patient. J Eur Acad Dermatol Venereol. 2020; 34 (8): e368-e370. doi: 10.1111/jdv.16620.

20. Shiohara T, Mizukawa Y. Comment on "Drug reaction with eosinophilia and systemic symptoms syndrome in a patient with COVID-19": involvement of herpesvirus reactivations and adverse drug reactions in diverse cutaneous manifestations and overall disease severity. J Eur Acad Dermatol Venereol. 2021; 35 (2): e98-e100. doi: 10.1111/jdv.16959.

21. Enos $T$, Jeong HS, Vandergriff $T$, Jacobe HT, Chong BF. Acute generalized exanthematous pustulosis induced by empiric hydroxychloroquine for presumed COVID-19. Dermatol Ther. 2020; 33 (6): e13834. doi: 10.1111/dth.13834.

22. Robustelli TE, Vezzoli P, Carugno A. Acute generalized exanthematous pustulosis with erythema multiforme-like lesions induced by hydroxychloroquine in a woman with coronavirus disease 2019 (COVID-19). J Eur Acad Dermatol Venereol. 2020; 34 (9): e457-e459. doi: $10.1111 / j d v .16613$.

23. Ayatollahi SA, Robati RM, Kamyab K, Firooz A. Late-onset AGEP-like skin pustular eruption following COVID-19: a possible association. Dermatol Ther. 2020; 33 (6): e14275. doi: 10.1111/dth.14275.

24. Lavery MJ, Bouvier CHA, Thompson B. Cutaneous manifestations of COVID-19 in children (and adults): a virus that does not discriminate. Clin Dermatol. 2020; 14 (40): 14-4.

25. Verdoni L, Mazza A, Gervasoni A, Martelli L, Ruggeri M, Ciuffreda M, Bonanomi E, D'Antiga L. An outbreak of severe Kawasaki-like disease at the Italian epicentre of the SARS-CoV-2 epidemic: an observational cohort study. Lancet: 2020 Jun 6;395(10239):17711778. doi: 10.1016/S0140-6736(20)31103

26. Sokolovsky S, Soni P, Hoffman T, Kahn P, Scheers-Masters J. COVID-19 associated Kawasaki-like multisystem inflammatory disease in an adult. Am J Emerg Med. 2021; 39: 253.e1-253.e2.

27. Labe P, Ly A, Sin C, Nasser M, Chapelon-Fromont E, Said PB et al. Erythema multiforme and Kawasaki disease associated with COVID-19 infection in children. J Eur Acad Dermatol Venereol. 2020; 34 (10): e539-e541.

28. Marraha F, Al Faker I, Gallouj S. A review of the dermatological manifestations of coronavirus disease 2019 (COVID-19). Dermatol Research and Practice. 2020; 9360476. doi: 10.1155/2020/9360476.

Conflicto de intereses: Sin conflicto de intereses. 